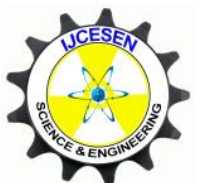

Copyright (C) IJCESEN
International Journal of Computational and

Experimental $\boldsymbol{S}$ cience and Engineering

(IJCESEN)

Vol. 5-No.1 (2019) pp. 27-30

http://dergipark.gov.tr/ijcesen

Research Article

\title{
Optimization of Traffic Signalization For Complex Roundabout By Fuzzy Logic According To Various Parameters
}

\author{
Tolga PALANDIZ ${ }^{1}$, Ramazan ŞENOL ${ }^{2}$, Hilmi Cenk BAYRAKÇI ${ }^{1}$ \\ ${ }^{1}$ Isparta University of Applied Sciences, Technology Faculty, Mechatronics Engineering Dept., 32200, Isparta-Turkey \\ ${ }^{2}$ Isparta University of Applied Sciences, Technology Faculty, Electric-Electronic Engin. Dept., 32200, Isparta-Turkey \\ * Corresponding Author : tolgapalandiz@gmail.com \\ ORCID: 0000-0003-0871-6129
}

\section{$\underline{\text { Article Info: }}$}

DOI: $10.22399 /$ ijcesen.446666

Received : 22 July 2018

Accepted : 05 January 2019

Keywords

Fuzzy logic

Intersection control

Traffic signalization

\begin{abstract}
$\underline{\text { Abstract: }}$
In this study, traffic signalization by fuzzy logic according to number of vehicles, vehicle type, fuel and time parameters of 5 leg roundabouts were simulated in computer environment. For this purpose, city surveillance cameras (mobese) were used for the selected intersection. In the simulation, the Mamdani type fuzzy model was used. The results of the application are listed in tables. According to the vehicle density coming near the intersection, the transition times or stopping times applied to the intersection were optimized. Also, types of vehicles coming near the intersection are analyzed and vehicles with high fuel consumption are given priority. Thus, fuel consumption and environmental pollution can be reduced. The methods in this study are compared in terms of fuel saving, environmental effects and faster road flow. Accordingly, neutral fuel consumption with fuzzy logic method is averagely \%15.9 less than classical method.
\end{abstract}

\section{Introduction}

Decision mechanisms of human didn't occur from "yes" and "no" like computers. In the face of relative situations every human has different answers. The basis of fuzzy logic occurred from fuzzy clusters. Fuzzy clusters are the most basic elements of fuzzy systems. The fuzzy set theory was described in the work of Zadeh [1]. There were so many studies made to improve signalization process at intersections. Artificial neural network and fuzzy logic were mainly used at designed systems. At 1977, Pappis and Mamdani were designed a decider model which was used signal circuit, queue length and extension time as parameters[2]. Tzes et al. were designed a traffic signal control for transportation networks at 1995 [3]. Tzes, McShane and Kim were improved a fuzzy logic based simulation model and they were compared this model with fixed time signalization [3]. Jongwan Kim by developing a simulation model for discrete and 4-phase supervised intersections with the help of their own developed control algorithm, were determined of difference from fixed time signalization [4]. Desai and Somani (2014), Hegyi et al. (2009), and Kuhne (1991), were determined different vehicle determination techniques based real-time sensor readings to help computer's vision at the solve of traffic congestion $[5,6,7]$. Some problems were emerged at the end of failure to provide effective traffic flow of conventional intersection systems. In this study, differences of fuzzy logic system and conventional system were revealed. Image processing is a computational process that transforms one or more input images into an output image [8]. Meng and Chen (2015) an approach to clustering analysis and multi-attribute decision making under hesitant fuzzy environment is developed, which can cope with the situations where the weight information is incompletely known and there exist interactions between attributes [9]. Chen et al. (2015) an improved $\mathrm{AB}$ model is presented and can be applied to all arrival cases. Through the membership function, the delay time of platoon can be computed for all arrival cases [10]. Czubenko et 
al. (2015) concern an adaptation of the ISD system to the role of an intelligent driver (xDriver), in a virtual environment [11]. The system processes vehicles with an image processing method in a fuzzy system as a car, a minibus and a truck which approach to a junction. Thus, number of various vehicles approaching to a junction and consumptive fuel quantity was compared with fuzzy logic rules and the most suitable transition time was aimed to calculate. In this method, the junction is controlled continuously in loops. Reducing traffic density at the intersection, decreasing fuel consumption while stopping by traffic lights and correspondingly minimizing savings, $\mathrm{CO}_{2}$ emission and protection of the environment shows that this method is more advantageous than the classical method.

\section{Application of Traffic Signalization with Fuzzy Logic}

The two most common methods used in traffic signalizations are fixed-time traffic signalizations and the second is traffic actuated signalization systems. In fixed-time signalization, the circuit durations and phase orders are predefined and the system works fixedly in this way. In traffic actuated method, circuit times and phase orders can be dynamically controlled and changed according to the intensity of traffic during different times of the day [12]. The intersection where the signalization is performed by the fuzzy logic method is given in Figure 1. $\mathrm{X}$ road is including A, D and C roads, and $Y$ road is including $B$ and $E$ roads. It is assumed that the traffic intensity of roads $\mathrm{A}, \mathrm{B}$ and $\mathrm{E}$ is higher than roads $\mathrm{C}$ and $\mathrm{D}$, and two main groups, $\mathrm{X}$ and $\mathrm{Y}$, are separated as in Figure 1. Here, A, D and $\mathrm{C}$ roads are treated as subcomponents of $\mathrm{X}$. Also $\mathrm{B}$ and $\mathrm{E}$ roads are treated as subcomponents of $\mathrm{Y}$. Input parameters for the generated fuzzy logicbased control; number of cars, minibuses, trucks and idle fuel quantities on the A, B, C, D and E roads. The output parameters are green light durations on the A, B, C, D, E roads. The algorithm of the installed system is given in Figure 2. The structure of $X$ in the system is shown in detail in Figure 3. Inputs and outputs on the $X$ road are determined. The structure of $\mathrm{Y}$ in the system is shown in detail in Figure 4. Inputs and outputs on the $\mathrm{Y}$ road are determined. Three different parameters are used for the fuzzifier process of the total number of vehicles on $\mathrm{X}$ road by fuzzy logic: low, normal and high. Values have been correlated with the numerical values in the case of monitoring of the intersection so as to increase the accuracy of the system. The fuzzifier process was also applied to the total amount of fuel consumed on $\mathrm{X}$ road and



Figure 1. Drawing of intersection.

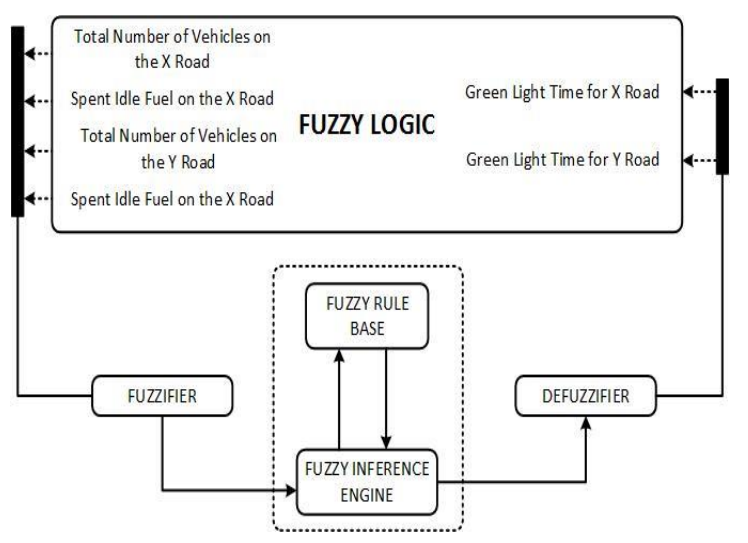

Figure 2. The algorithm of the installed system.

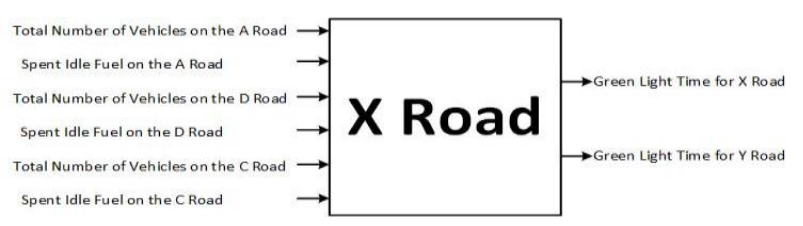

Figure 3. Inputs and outputs on the X road.

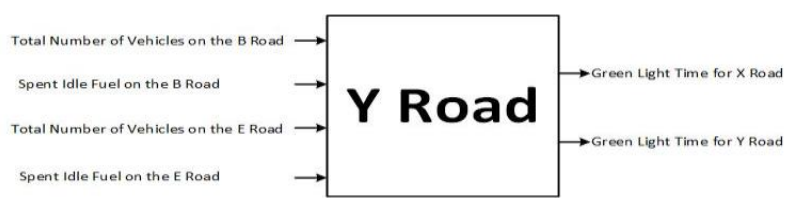

Figure 4. Inputs and outputs on the Y road.

the duration of green light on $\mathrm{X}$ road. The distribution of roads by vehicle type is given in Table 1. The values given are taken from real life. Waiting times vary for each road in the intersection where the simulation is performed. Therefore, the values given in Table 2 are equal to the amount of fuel in liters/ second spent waiting until the end of the lap on the road where the vehicles under examination reside.

\section{Conclusion}

At the simulation 17 laps were investigated and 1 lap was taken as 107 seconds, so the system was observed for about half an hour. 
Table 1. Distribution of roads by vehicle types.

\begin{tabular}{|c|c|c|c|c|c|c|c|}
\hline Laps & 1 st & 2nd & 3 rd & $\ldots$ & 15 th & 16 th & 17 th \\
\hline Car (X) & 43 & 47 & 55 & $\ldots$ & 48 & 48 & 34 \\
\hline Minibus (X) & 4 & 1 & 2 & $\ldots$ & 0 & 5 & 4 \\
\hline Truck (X) & 1 & 0 & 1 & $\ldots$ & 0 & 0 & 0 \\
\hline Car (A) & 19 & 26 & 23 & $\ldots$ & 20 & 16 & 17 \\
\hline Minibus (A) & 1 & 0 & 1 & $\ldots$ & 0 & 2 & 1 \\
\hline Truck (A) & 1 & 0 & 1 & $\ldots$ & 0 & 0 & 0 \\
\hline Car (D) & 10 & 4 & 9 & $\ldots$ & 4 & 9 & 4 \\
\hline Minibus (D) & 2 & 1 & 1 & $\ldots$ & 0 & 2 & 3 \\
\hline Truck (D) & 0 & 0 & 0 & $\ldots$ & 0 & 0 & 0 \\
\hline Car (C) & 14 & 17 & 23 & $\ldots$ & 24 & 23 & 13 \\
\hline Minibus (C) & 1 & 0 & 0 & $\ldots$ & 0 & 1 & 0 \\
\hline Truck (C) & 0 & 0 & 0 & $\ldots$ & 0 & 0 & 0 \\
\hline Car (Y) & 25 & 19 & 22 & $\ldots$ & 15 & 20 & 26 \\
\hline Minibus (Y) & 1 & 0 & 0 & $\ldots$ & 0 & 0 & 0 \\
\hline Truck (Y) & 0 & 3 & 4 & $\ldots$ & 3 & 2 & 4 \\
\hline Car (B) & 15 & 9 & 11 & $\ldots$ & 9 & 12 & 10 \\
\hline Minibus (B) & 1 & 0 & 0 & $\ldots$ & 0 & 0 & 0 \\
\hline Truck (B) & 0 & 1 & 2 & $\ldots$ & 2 & 2 & 0 \\
\hline Car (E) & 10 & 10 & 11 & $\ldots$ & 6 & 8 & 16 \\
\hline Minibus (E) & 0 & 0 & 0 & $\ldots$ & 0 & 0 & 0 \\
\hline Truck (E) & 0 & 2 & 2 & $\ldots$ & 1 & 0 & 4 \\
\hline
\end{tabular}

Table 2. Amount of idle fuel spent on roads by vehicle types.

\begin{tabular}{|c|c|c|c|c|c|c|c|}
\hline Laps & 1 st & 2nd & 3rd & $\ldots$ & 15 th & 16 th & 17 th \\
\hline Car (X) & 0.38 & 0.42 & 0.49 & $\ldots$ & 0.43 & 0.43 & 0.3 \\
\hline Minibus (X) & 0.11 & 0.02 & 0.05 & $\ldots$ & 0 & 0.14 & 0.11 \\
\hline Truck (X) & 0.04 & 0 & 0.04 & $\ldots$ & 0 & 0 & 0 \\
\hline Car (A) & 0.17 & 0.23 & 0.2 & $\ldots$ & 0.18 & 0.14 & 0.15 \\
\hline Minibus (A) & 0.02 & 0 & 0.02 & $\ldots$ & 0 & 0.05 & 0.02 \\
\hline Truck (A) & 0.04 & 0 & 0.04 & $\ldots$ & 0 & 0 & 0 \\
\hline Car (D) & 0.14 & 0.05 & 0.12 & $\ldots$ & 0.05 & 0.12 & 0.05 \\
\hline Minibus (D) & 0.08 & 0.04 & 0.04 & $\ldots$ & 0 & 0.08 & 0.13 \\
\hline Truck (D) & 0 & 0 & 0 & $\ldots$ & 0 & 0 & 0 \\
\hline Car (C) & 0.18 & 0.22 & 0.31 & $\ldots$ & 0.32 & 0.31 & 0.17 \\
\hline Minibus (C) & 0.04 & 0 & 0 & $\ldots$ & 0 & 0.04 & 0 \\
\hline Truck (C) & 0 & 0 & 0 & $\ldots$ & 0 & 0 & 0 \\
\hline Car (Y) & 0.34 & 0.26 & 0.3 & $\ldots$ & 0.2 & 0.27 & 0.35 \\
\hline Minibus (Y) & 0.04 & 0 & 0 & $\ldots$ & 0 & 0 & 0 \\
\hline Truck (Y) & 0 & 0.2 & 0.27 & $\ldots$ & 0.2 & 0.13 & 0.27 \\
\hline Car (B) & 0.2 & 0.12 & 0.15 & $\ldots$ & 0.12 & 0.16 & 0.13 \\
\hline Minibus (B) & 0.04 & 0 & 0 & $\ldots$ & 0 & 0 & 0 \\
\hline Truck (B) & 0 & 0.06 & 0.13 & $\ldots$ & 0.13 & 0.13 & 0 \\
\hline Car (E) & 0.13 & 0.13 & 0.15 & $\ldots$ & 0.08 & 0.11 & 0.22 \\
\hline Minibus (E) & 0 & 0 & 0 & $\ldots$ & 0 & 0 & 0 \\
\hline Truck (E) & 0 & 0.13 & 0.13 & $\ldots$ & 0.06 & 0 & 0.27 \\
\hline
\end{tabular}

Moreover, in figure 5 neutral fuel consumptions, which were obtained from fuzzy methods, were calculated and compared according to the literature $[13,14,15]$. Around the world the energy systems are mainly based on fossil fuels. However, in the near future, as a result of excessive use, the sources of fuel will start to decrease and this will lead to a search of new reserves and invention of new Technologies [16]. However, in the near future, as a result of excessive use, the sources of fuel will start to decrease and this will lead to a search of new reserves and invention of new technologies [17]. In this study, per lap fuel consumptions were calculated in terms of liter/second. Accordingly, neutral fuel consumption with fuzzy logic method is averagely \%15.9 less than classical method. According to the data which were obtained from Figure 5, approximately 5.82 liter fuel saving was provided in one hour with the usage of fuzzy logic method. Plus, 3.7 tone $\mathrm{CO}_{2}$ emission can be prevented or 167.8 trees can be saved. By this means, per hour $8.61 \$$ economic loss can be resolved. If we write these values daily or annually by supposing that the traffic is daily averagely crowded for 10 hours, respectively on a daily basis fuel consumption, economic profits, $\mathrm{CO}_{2}$ emission and saved trees will be 58.2 liter, 86.1\$, 37 tone and 1678.

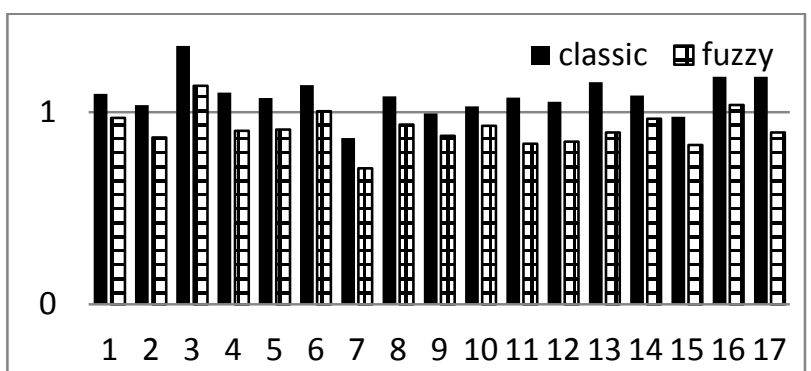

Figure 5. Comparison of fuzzy logic and classical method in terms of idle fuel consumption.

Respectively on annual basis, fuel consumption, economic profits, $\mathrm{CO}_{2}$ emission and saved trees will be 21243 liter, 31426.5 \$, 13505 tone and 612470 .

\section{References}

[1] L.A. Zadeh, Inform. Control 8, 338 (1965).

[2] Pappis, C.P.,Mamdani, E.H., A Fuzzy Logic Controller for a Traffic Junction, IEEE Transactions on systems, Man and Cybernetics, 707-717,(1977).

[3] Tzes A., McShane and Kim, S., Expert Fuzzy Logic Traffic Signal Control for Transportation Networks, Institute of Transportation Engineers 65th Annual Meeting, Denver USA, 154-158, (1995).

[4] Kim, Jongwan, A Fuzzy Logic Control Simulator for Adaptive Traffic Management, Proc IEEE International Conference on Fuzzy Systems, 15191524, (1997).

[5] Desai, D., Somani, S., 2014. Instinctive traffic control and vehicle detection techniques. 
International Journal of Scientific \& Engineering Research 5 (1), 2192-2195.

[6] Hegyi, A., Bellemans, T., De-Schutter, B., 2009. Freeway traffic management and control, In: Meyers, R.A. (Ed.), Encyclopaedia of Complexity and Systems Science. Springer, New York, pp. 3943-3964.

[7] Kuhne, R.D., 1991. Freeway control using a dynamic traffic flow model and vehicle reidentification techniques. Transportation Research Record 1320, 251-259.

[8] N.G. Adar*, A. Egrisogut Tiryaki and R. Kozan, , Acta Phys. Pol. A 128, B-348(2015)

[9] F. Meng, X. Chen, 2015. Correlation Coefficients of Hesitant Fuzzy Sets and Their Application Based on Fuzzy Measures, Cognitive Computation, August 2015, Volume 7, Issue 4, pp 445-463.

[10] F. Chen, L. Wang, B. Jiang, C. Wen, 2015. An Arterial Traffic Signal Control System Based on a Novel Intersections Model and Improved Hill Climbing Algorithm, Cognitive Computation, August 2015, Volume 7, Issue 4, pp 464-476.

[11] M. Czubenko, Z. Kowalczuk, A. Ordys, 2015. Autonomous Driver Based on an Intelligent System of Decision-Making, Cognitive Computation, October 2015, Volume 7, Issue 5, pp 569-581.

[12] Şimşir, F., Özkaynak, E., Ekmekçi D., "Kavşaklarda Trafik Sinyalizasyon Sisteminin Modellemesi ve Benzetimi”, Akademik Bilişim, (2013).

[13] https://www.anl.gov/sites/anl.gov/files/idling_work sheet.pdf(Access Date: 21.08.2017)

[14] www.cleancities.energy.gov (Access Date: 21.08.2

017)

[15] https://www.afdc.energy.gov(Access Date: 21.08.2

017)

[16] O.M. Pişirir and O. Bingöl, Acta Phys. Pol. A 130, 36 (2016)

[17] B. Kiriş, O. Bingöl , R. Şenol and A. Altintaş, Acta Phys. Pol. A 130, 55 (2016) 